medgen $2008 \cdot 20: 30-31$

DOI 10.1007/s11825-008-0083-1

Online publiziert: 16. Februar 2008

(c) Springer Medizin Verlag 2008

\author{
E. Passarge ${ }^{1} \cdot$ H.H. Ropers ${ }^{2}$ \\ ${ }^{1}$ Institut für Humangenetik, Universitätsklinikum Essen \\ ${ }^{2}$ Max-Planck-Institut für molekulare Genetik, Berlin
}

\title{
Holger Höhn, Professor emeritus (aktiv)
}

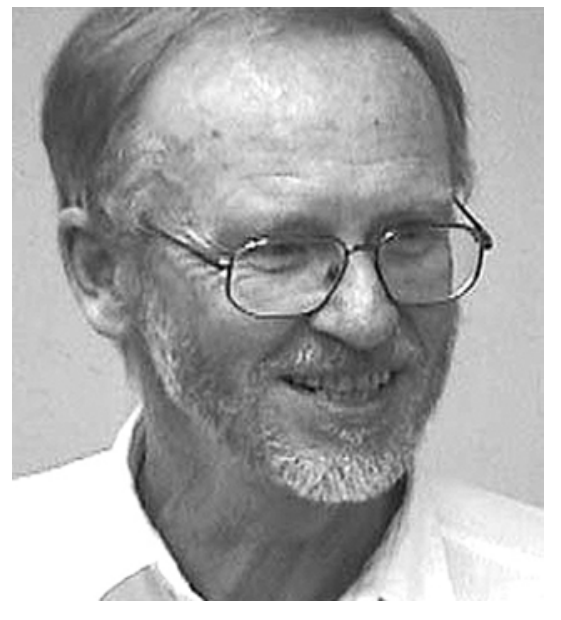

(Foto: R. Dietrich, Deutsche Fanconi-AnämieHilfe e.V.)

Angesichts seiner jugendlichen, ja jungenhaften Ausstrahlung fällt es schwer, zu glauben, dass Holger Höhn bereits (seit dem 28. Dezember 2007) 65 Jahre alt ist und in wenigen Wochen, Ende März 2008, als Ordinarius für Humangenetik an der Universität Würzburg emeritiert wird. Er hat das Würzburger Humangenetik-Institut aufgebaut und mehr als 27 Jahre geleitet, und nicht zuletzt aufgrund seiner internationalen Anerkennung, aber auch als Vorsitzender unserer Fachgesellschaft (von 1996 bis 1998) hat er sich um die deutsche Humangenetik verdient gemacht.

Geboren in Sonneberg, Thüringen, verbrachte er einen Großteil seiner Jugend bei seinem kinderlosen Onkel in Würzburg, da sich seine Mutter in der DDR nicht in der Lage sah, drei Kinder ohne Vater allein großzuziehen. Nach einem Medizinstudium (von 1962 bis 68) in Würzburg und Innsbruck erhielt er (von 1968 bis 1971) seine humangenetische Orientie- rung im Freiburger Institut, unter Leitung von Prof. Helmut Baitsch und besonders von Prof. Ulrich Wolf, dessen Gestus ihn (wie auch viele andere ehemalige Mitarbeiter) nachhaltig geprägt hat. Die damalige, für Deutschland einzigartige „Dichte“ an Nachwuchswissenschaftlern am Freiburger Institut bewog ihn bereits nach wenigen Jahren, nach Amerika umzusiedeln und sich (von 1971 bis 1979) der Gruppe von George M. Martin am Department of Pathology und Arno G. Motulsky am Center for Inherited Diseases der University of Washington in Seattle anzuschließen. Diesen Schritt hat er nie bereut, und mit einem leichten Anflug von Ironie ist er heute noch allen dankbar, die ihn seinerzeit dazu veranlasst haben.

Am 1. November 1979 wurde Holger Höhn auf den neuen Lehrstuhl für Humangenetik in Würzburg berufen; als Gründungsjahr des Instituts gibt er 1980 an. Damals war Würzburg der letzte Lehrstuhl in einer Serie von Wieder- bzw. Neugründungen in der Bundesrepublik nach dem zweiten Weltkrieg (1951 Münster, 1956 Kiel, 1962 Heidelberg und Tübingen, 1963 Marburg und Frankfurt, 1965 Freiburg und Erlangen, 1967 Gießen, 1972 Hannover, 1973/74 Ulm, Homburg/Saar, Lübeck, 1976 Essen und FU Berlin) und der DDR (Humboldt Berlin, Greifswald, Jena, Halle, Leipzig, Erfurt, Magdeburg, sowie mehrere Bezirkskrankenhäusern). Das neue Institut in Würzburg war klein, ein Provisorium von gerade $320 \mathrm{~m}^{2}$ in der Koellikerstraße. In das Guinnessbuch der Rekorde gelangte das fensterlose Arbeitszimmer von $3,5 \mathrm{~m}^{2}$ des Institutsdirektors. Es ist das Verdienst des Gründungsdirektors und mehrerer ihn aus Seattle begleitenden Mitarbeiter (D. Salk, K. Au, P.
Johnston, B. Inglin, C. Maxwell), aus diesen bescheidenen Anfängen unverzagt ein modernes Institut aufgebaut zu haben.

In den Jahren 1986 und 1987 besserte sich die räumliche Situation etwas. Der 1991 erfolgte Umzug in das neue Biozentrum Am Hubland löste das Raumproblem nicht grundsätzlich, denn noch immer standen zunächst nur $577 \mathrm{~m}^{2}$ verteilt auf zwei Stockwerke und $86 \mathrm{~m}^{2}$ geliehene Laborflächen zur Verfügung. 1997 wurde die eigenständige Abteilung Medizinische Genetik unter Leitung von Tiemo Grimm gegründet, und 2001 erfolgte dann die Erweiterung um ca. $300 \mathrm{~m}^{2} \mathrm{mit}$ dem Verfügungsgebäude für die neue Abteilung und die Institutsverwaltung.

Für seine Berufung im Alter von erst 37 Jahren hatte sich Herr Höhn mit 48 zwischen 1969 und Mitte 1979 erschienenen wissenschaftlichen Arbeiten zu Themen aus der modernen Cytogenetik, der Zellkultur und Somazellgenetik und der Pränataldiagnostik qualifiziert, ergänzt durch Beiträge zur Analyse von Heterochromatin und zum Marker X-Chromosom bei geistiger Behinderung. Als einer der ersten Humangenetiker hat er sich intensiv mit der Durchflusszytometrie befasst (J. Callies \& H. Hoehn, Am.J.Hum.Genet. 28: 577-588, 1976; H. Hoehn, P. Johnston, J. Callies, Cytogenet.Cell Genet.19: 163-168, 1977), und auch heute noch sehr lesenswert sind seine wichtigen Arbeiten zur funktionellen Bedeutung chromosomaler Bändermuster (H. Hoehn, Am.J.Hum.Genet. 27: 676-686, 1975; D.M. Kurnit \& $H$. Hoehn, Ann. Rev. Genet. 13: 235-258, 1979). Aus dieser Zeit besonders hervorzuheben sind auch seine Untersuchungen zur zellulären Alterung beim Werner-Syndrom (T.H. Norwood, H. Hoehn, G.M. Martin, J. 
invest Dermatol. 73: 92-96, 1979) und der Nachweis einer normalisierten Rate von SCEs in Zellhybriden von Bloom-Syndrom und normalen Zellen (E.M. Bryant, H. Hoehn, G.M. Martin, Nature 279: 795796, 1979).

Die meisten dieser Untersuchungen wurden in Würzburg unmittelbar fortgesetzt, ohne erkennbare, durch den Aufbau des Instituts bedingte Unterbrechung der Publikationstätigkeit. Neben Beiträgen zur Pränataldiagnostik folgten zwischen 1980 und 200610 Originalarbeiten über zelluläre, chromosomale und klinische Aspekte des Werner-Syndroms, dazu 15 Arbeiten über die maßgeblich von $\mathrm{Hol}$ ger Höhn mit entwickelten Methode der Durchflusszytometrie und zahlreiche andere thematisch und methodisch verwandte Arbeiten. Die systematische Entwicklung der wissenschaftlichen Tätigkeit Höhns zeigt sich in nicht zu übertreffender Weise in den zwischen 1981 und 2007 erschienenen 20 Arbeiten zu Fanconi-Anämie, Ataxia-telangiectatica und Nijmegen-Breakage-Syndrom (4) und Bloom-Syndrom (3), neben den bereits erwähnten 10 Arbeiten über das WernerSyndrom. Allein die Arbeit von M. Poot, $H$. Hoehn et al. (Impaired S-phase transit of Werner syndrome cells expressed in lymphoblastoid cell lines, Exp Cell Res. 202: 267-273, 1992) wurde 131-mal zitiert ( $M$. Poot, persönl. Mitteilung). Eine jüngst erschienene Arbeit über die „Functional role of the Werner syndrome RecQ helicase in human fibroblasts" (M. Poot et al., Aging Cell 6: 53-61, 2007) ohne formelle Co-Autorschaft von Herrn Höhn geht auf seine zahlreichen Vorarbeiten zurück.

So beeindruckend dieses etwa 140 wissenschaftliche Arbeiten umfassende Schriftenverzeichnis auch ist, es wird übertroffen von der Liste der Arbeiten aus dem Institut Würzburg, in denen Herr Höhn nicht als Co-Autor aufgeführt ist. Diese lange Liste ist ein Ausdruck der von ihm gewollten und geförderten Eigenständigkeit seiner gegenwärtigen und früheren Mitarbeiter, die dem Institut zusammen mit ihm selbst internationale Geltung verschafft haben: $T$. Grimm (Klinische Genetik), D. Schindler, M. Kubies, M. Poot (Somazellgenetik), M. Schmid (Zytogenetik und Evolution; Herausgeber wichtiger Zeitschriften), C. Mül-
ler-Reible mit W. Kress, G. Meng, T. Bettecken und andere (Molekulare Genetik der Neuromuskulären Krankheiten), B. Weber mit H. Stöhr und andere (Ophthalmologische und onkologische Humangenetik), T. Haaf (molekulare und zelluläre Genetik), U. Felbor (Genetik von Gefäßerkrankungen). Er, der Unkonventionelle, der in keiner Hinsicht dem Klischeebild eines deutschen Ordinarius entspricht, hat sie alle und andere, hier nicht genannten Mitarbeiter und Mitarbeiterinnen mit sanfter Hand zusammengeführt und -gehalten, und nicht wenige hat er für die Humangenetik gewinnen können. Darin sehen wir eine bedeutende Leistung, die Anerkennung verdient.

In zahlreichen Buchbeiträgen and anderen Schriften hat sich Höhn mit ethischen und weltanschaulichen Fragen der Humangenetik auseinandergesetzt. Um so befremdlicher waren die zwischen 1997 und 2000 gegen ihn erhobenen Anschuldigungen wegen vorgeblich unerlaubter Untersuchungen an geistig Behinderten. Ausgerechnet er, der in besonderer Weise von den Zeitläuften geprägte, der Philosophie und Poesie zugetane Arzt, der über die moralisch-ethischen Aspekte des humangenetischen Handelns mehr nachgedacht hat als die Meisten von uns, war lange Jahre gezwungen, sich gegen eine Verleumdungskampagne zu wehren, welche die Existenz seines Instituts bedrohte, aber genauso gegen die Humangenetik gerichtet war. Wir haben allen Grund, ihm und seinem loyalen Mitstreiter Tiemo Grimm, alles andere als esoterisch veranlagt und in vieler Hinsicht sein Gegenentwurf, dafür dankbar zu sein, diese zahlreichen gerichtlichen Auseinandersetzungen durchgestanden und schließlich gewonnen $\mathrm{zu}$ haben.

Seither ist es in Deutschland nicht mehr so einfach, die humangenetische Forschung zu dämonisieren und als Fortsetzung eugenischer Praktiken des „Dritten Reichs“ zu diffamieren. Es ist ein gutes Zeichen, dass die Erforschung der genetischen Ursachen kognitiver Störungen, welche auf deren Prävention und Therapie zielt, aber ohne eine Untersuchung Betroffener nicht möglich ist, in Deutschland seit kurzem nicht nur toleriert, sondern sogar (im Rahmen des Nationalen Genomforschungsnetzwerks) mit öffent- lichen Mitteln gefördert wird. Zweifellos haben Höhn und Grimm an dieser positiven Entwicklung wesentlichen Anteil.

Zum Glück war es Herrn Höhn wenigstens in den allerletzten Jahren vergönnt, sich wieder den normalen $\mathrm{Ge}$ schäften eines Institutsleiters, Hochschullehrers und Forschers zu widmen. Ein (nicht nur für ihn selbst) erfreuliches Ergebnis dieser Entspannung ist der kürzlich gemeinsam mit $D$. Schindler herausgegebene Band zum Thema „Fanconi Anemia“, erschienen bei Karger, 2007.

Wir wünschen uns, dass er sich nach seiner Emeritierung nicht gänzlich aus der Wissenschaft zurückziehen möge. Angesichts seiner unverminderten Spannkraft und seinem (kolportierten) Wunsch nach ewiger Jugend sieht es zum Glück nicht danach aus.

\section{Eberhard Passarge \\ und \\ Hans Hilger Ropers}

\section{Korrespondenzadresse \\ Prof. Dr. E. Passarge}

Institut für Humangenetik,

Universitätsklinikum Essen,

Hufelandstraße 55,

45122 Essen

eberhard.passarge@uni-due.de

Danksagung. Herrn Grimm (Würzburg) und Herrn Schinzel (Zürich) gilt unser Dank für hilfreiche Hinweise und Anregungen zum Verfassen dieser Laudatio. 